\title{
Where Affinity Meets Practice: Emerging Communities of Practice to Meet the Needs of Korean IT Professionals
}

\author{
Ada Kim \\ The Information School, University of Washington \\ kimsk@uw.edu
}

\begin{abstract}
The growing Information Technology (IT) international workforce in the US has diverse social and professional needs. Organizations offer support structures such as Affinity Groups (AGs) and Communities of Practice (CoPs) to provide social support, learning and mentoring opportunities for their members. In this paper, we examine an emerging form of a grass-root inter-organizational groups that provide such support for Korean IT employees. The paper reports on the preliminary findings of a case study of Changbal (CB), a professional and social community that combines the characteristics of AGs and CoPs. Our research examines the characteristics of $\mathrm{CB}$, how the community supports employees to transition to the US workplace, and differences between $C B$ and other AGs or CoPs. The paper reports on the implications of this new form of community on our understanding of CoPs and AGs and practical implications of the IT industry.
\end{abstract}

\section{Introduction}

The migrant workforce in the Information Technology (IT) sector of the US labor market is on the rise. In 2016, the number of H1B visas, employment visas for persons in specialty occupation such as IT, issued increased by approximately 40\% [1]. In 2014, $64.5 \%$ of approved H1B visa petitions were for computer-related occupations [2]. Technology firms are the main beneficiaries of $\mathrm{H} 1 \mathrm{~B}$ visas and utilize them to address the shortage for IT talent in the US [3].

The growing migrant workforce presents a diverse set of social, cultural, and professional opportunities and challenges for successful socialization into the US work environment. To meet migrant employees' social needs, organizations provide support structures such as Affinity Groups (AGs), voluntary groups whose members share common interests and attributes [4, 5, 6]. AGs originated to support historically marginalizes populations and evolved to provide an avenue for employees with common interests (e.g., sports, hobbies)

\author{
Hala Annabi \\ The Information School, University of Washington \\ hpannabi@uw.edu
}

to develop social connections in order to develop a sense of belonging $[4,5,6]$. Communities of Practice (CoPs) $[7,8]$ is another mechanism that provides potential opportunities for learning and mentoring for these migrant professionals in the IT industry. CoPs provide employees the opportunity to keep pace with the dynamic and continually evolving nature of IT knowledge and practice.

An emerging phenomenon in IT hubs such as Seattle and Silicon Valley is the creation of CoPs with membership limited to South Korean migrant IT professionals. K-group in Silicon Valley and Changbal (CB) in Seattle, are communities that emerged through grassroots efforts by Korean IT professionals hoping to create learning and support networks for others like them.

The emerging phenomenon raises questions about the differences between groups like CB and K-group and Korean AGs or IT CoPs that already exist in IT firms and why migrant IT workers like the Korean IT workers in Seattle and Silicon Valley initiate such groups in place or in addition to the existing forms of CoPs and AGs. To this end, the authors initiated an indepth case study of $\mathrm{CB}$ to explore these research questions. This paper reports on the preliminary findings from the case study.

In the next section of the paper, we review the literature on AGs and CoPs, and CoPs in the IT industry. In section 3, we present our methodology and a detailed description of our case study CB. In section 4, we highlight the main preliminary findings of the study based on AG and CoP dimensions and processes. The paper concludes with a discussion of CB characteristics and insights regarding the implications of such form of Affinity Community of Practice (ACoP).

\section{Literature review}

To explain the emerging communities like Changbal, we review the literature on Affinity Groups (AGs) and Community of Practice (CoPs). We also 
review more recent literature that elucidates the impact of CoPs on the Information Technology (IT) industry.

\subsection{Affinity Groups}

In their most traditional form, AGs are communities of employees who share common individual characteristics, such as gender, race, ethnicity, sexual orientation, religion, or nationality [4, 6]. AGs are often formed by a grassroots effort by employees who determine a need and create self-led groups in a specific organizational context [5]. Membership in AGs is voluntary $[9,10]$. The origin of AGs dates back to the National Black Employees Caucus formed in 1970 at Xerox and inspired by the 1964 race riot. Xerox developed the caucus to support black employees and address issues of discrimination [4]. More recently, AGs form around a wider set of characteristics, such as interests (e.g., sports, service), professional roles (e.g., administrators), or personal roles (e.g., moms, dads) [11, 12] to support employees and enhance their experience and engagement in intra-organizational context.

Contemporary AGs serve several purposes for the organization and their members. Consistent with their original form, AGs continue to be a very common diversity and inclusion (D\&I) intervention to provide support for marginalized groups and improve their inclusion in organizations. Goode [11] in his study of AGs found that more than $70 \%$ of organizations that support AGs relied on them to partner with D\&I leaders to carry out diversity goals. The Mercer report [13] identified at least three specific ways in which AGs serve D\&I strategies: (1) as focus groups to provide feedback for D\&I strategists, (2) to implement specific strategies, such as mentoring and onboarding, and 3) as agents of cultural change in the organization.

More contemporary AGs facilitate interaction and social engagement to provide support and address issues of common interest beyond the D\&I focus [12]. Welbourne and McLaughlin [12] identified three types of purposes that AGs serve: social-cause centered, professionally-centered, and attribute-centered. Socialcause focused AGs are formed to bring together employees who wish to support public and social good (e.g., environmental work, cancer). This type of AGs fulfills employees' need of being part of something bigger than themselves [14]. Professionally-centered AGs are formed by employees in a similar professional role (e.g., designers, engineers, or administrative staff) in the organizations to support their professional development [5]. Attribute-centered AGs are a more traditional form of AGs that focus on personal characteristics or demographics (e.g., women, LGBT) and serve the different D\&I goals discussed in the first paragraph of this section $[9,15,16]$. The focus of this paper is attribute-centered AGs.

In general, AGs address and evolve through four dimensions (or evolutionary iterative phases): awareness (deciding numbers and characteristics), affiliation (community building and connecting), access (diversity of network increases and structured mentoring appears), and advancement (education, training, and leadership) [4]. Such formal characteristics in governing and structuring AGs influence employees' identities [12]. Among several identities the AG members have, organization (commitment to company) and innovation (building and spreading new ideas) identity were the strongest [12].

\subsection{Communities of Practice}

Communities of Practice (CoPs) are "groups of people who share a concern or a passion for something they do and learn how to do it better as they interact regularly" [17:1]. In general, novice and non-expert members of a community learn through interaction with and observation of expert members in the community, eventually becoming contributing members and full participants. The concept of CoPs emerged from the study of apprenticeship as a learning model [7]. The main purpose of CoPs is to enhance members' capabilities through learning across members within the community [18]. A secondary purpose of CoPs emphasizes enhanced business performance through information sharing and knowledge management [8].

Membership in CoPs is voluntarily and driven by individual interest, which leads to a variety of participation styles and formats. Therefore, CoPs often hold few formally-defined objectives and goals and relatively undefined boundary/membership in the community [18]. CoPs, therefore, come in a variety of forms in terms of size (i.e., large or small), proximity (i.e., local or global), ubiquity (i.e., online or offline), and popularity (i.e., well-recognized or not) [18]. In terms of organizational context, CoPs, unlike AGs, may be inter-organizational or intra-organizational and may or may not be linked directly to formal business objectives [19]. Early studies (in the 1990's) of CoPs emphasized their organic, autonomous, voluntary and fluid nature [20]. Later studies of CoPs, however, recognized their strategic organizational benefits and emphasized organizational sponsorship and involvement in knowledge management strategy [19].

Wenger [21] defined three dimensions of CoPs: domain, community, and practice. Domain represents a specific field of shared interest in which members develop commitment and expertise, a distinct difference between CoPs and a network of connections or friendship-based social groups. Community is defined 
by the mutual engagement of community members in knowledge and information sharing through interactions. Practice is "a shared repertoire of resources including experiences, tools, and ways of addressing recurring problems" [17:2], which should be regular and sustained over time. One important feature of CoPs is legitimate peripheral participation [7], a process in which novice and non-experts becomes experts in a particular domain through guided practice and feedback.

\subsection{AGs and CoPs in the information technology (IT) industry for migrant IT professionals}

Wenger, McDermott, and Snyder [18] stressed that knowledge management is dynamic because it requires continuous up-to-date contributions from members. Brown and Duguid also emphasized that "learning is inseparable from working" [22:46], and "learning is fostered by fostering access to and membership of the target community-of-practice, not by explicating abstractions of individual practice" [22:49-50]. These characteristics of learning are especially relevant to the IT industry. Recently, scholars indicated that CoPs play an important role in integrating and utilizing new knowledge from rapidly developing technology to the IT field's innovative nature. To keep connecting baseline and leading edge knowledge, continuous learning and collaboration across IT professionals with diverse expertise is necessary [18], [23, 24, 25]. Therefore, inter-organizational CoPs are especially suitable for the IT industry.

For CoPs in IT, being inter-organizational is critical in order to facilitate knowledge flow across individuals and organizations and eventually contribute to the learning experience of both [25, 26]. Powell, Coput and Smith-Dorr [24], for example, studied networks in biotechnology and how they contributed to organizational learning on the firm level. Their findings revealed that establishing networks across firms improved the flow of information resources. Furthermore, the study revealed that collaboration practices with various partners created and facilitate learning. At the individual level, Benner [23] investigated how Silicon Valley Webgrrls (SVW), one of the largest cross-firm informal CoPs, provides context for individuals to learn and develop their careers in IT in Silicon Valley. The study revealed that CoPs such as SVW help "newcomer to the industry to rapidly learn and update the skills and knowledge they needed" [23:1826]. Benner emphasized that a high level of vibrancy, trust, and openness was key to the success of an individual's effective learning within a community.

Two factors that influence the effectiveness of interorganizational CoPs are proximity and diversity. Proximity affects how inter-organizational CoPs in IT support the learning experiences of its members. Knoben \& Oerlemans [27] suggested three dimensions of proximity that influences inter-organizational collaboration: technological, geographical, and organizational. Technological proximity refers to the level of overlapping knowledge base, geographical proximity refers to maintaining face-to-face relations without prohibitive costs, and organizational proximity refers to cooperation which does not require additional coordination or definition, "which is a prerequisite for dyadic and collective learning" [27:75].

Diversity is the second factor that may facilitate or hinder the learning experiences created within CoPs, which is critical for the IT Industry. Diverse and homogenous groups reveal different types of strengths [28]. Ethnically homogenous groups share the same cultural norms and this facilitates efficient communications within a group, leading to improved effectiveness in performance in its early stage [28], [29]. On the other hand, diverse groups emphasize the importance of interpersonal leadership to manage interactions among diverse members [28], which produces better learning outcomes if differences are managed productively [30, 31, 32, 33].

Our understanding of AGs in general, and in the context of the IT industry in particular, is limited. Major IT organizations rely on AGs to advance D\&I goals and enhance recruitment, retention and advancement of marginalized groups [13], but we know little about the means and the outcomes of AGs in IT. Welbourne et al. [6] suggests that very few studies have investigated attribute-centered AGs in general and in IT in particular $[9,16,34]$.

\subsection{Literature Review Summary}

The literature considers AGs and CoPs separately. Nonetheless, our review revealed important differences and similarities between attribute-based AGs and CoPs. These are summarized in Appendix A. Most significant differences between AGs and CoPs, lies in their purpose and their dimensions. While AGs focus on providing social support and a platform for D\&I, CoPs concentrate on enhancing the capabilities of individuals and organizations through learning the common domain practices. Both AGs and CoPs emphasize community engagement through interaction (CoPs centers on apprenticeship and AGs centers on sharing and mentorship relating to share attribute).

The literature review also revealed that AGs and CoPs are prevalent and serve important roles in the IT industry. The literature revealed the importance of domain and geographic proximity and diversity for the effectiveness of learning and engagement in IT CoPs. Furthermore, for CoPs to be effective, they must take 
members' socio-cultural backgrounds into consideration [35].

The differences and similarities between AGs and CoPs provide a framework by which to analyze CB. This study provides a revelatory case to understand the catalyst for creating an inter-organizational CoP that is also an AG. Therefore, this research addresses a gap in the literature by elucidating the nature of emerging groups within the IT industry that combine features of AGs and CoPs to serve migrant employees in the IT industry. More specifically, this research aims to address the following research questions:

(1) What are the characteristics of CB?

(2) What are the major differences between $\mathrm{CB}$ and other AGs or CoPs that exist within CB members' organizations?

(3) How does CB support employees to adapt their prior working experiences to the US workplace?

\section{Methodology}

To better understand the emerging phenomenon of inter-organizational CoPs/nationality-based AGs in the IT domain, we use the case study method. The case study method is most appropriate when investigating "a contemporary phenomenon within its real-life context; when the boundaries between phenomenon and context are not clearly evident; and in which multiple sources of evidence are used" [36:23]. We employed a holistic single-case study design to explore the revelatory case $\mathrm{CB}$, an affinity group created by Korean employees working in IT organizations in the greater Seattle area.

\subsection{Changbal (CB)}

CB is "a Korean IT Professional Society in Greater Seattle area.” The name, "Changbal”, means creativity, invention, and emergence. According to their website, "Changbal Society started in 2014 as a forum where like-minded Korean and Korean American professionals involved in technology in Seattle area can learn, network and grow.” Since 2014, CB has grown into an active community with 134 registered members running more than 20 seminars. Each seminar attracts 30 to 40 attendees. In 2016, CB was officially registered as a non-profit organization (NPO) in the US under the name of "Changbal Society."

As of June 2017, CB included 230 members in its mailing list and 380 members on the CB Facebook group, with a wide range of IT expertise summarized in Table 1. To accommodate the growth in membership and meet the interests of the diverse members' backgrounds, CB created subgroups organized into three areas of IT expertise, including developer group, entrepreneur group (kickstarter), and designer group.
More recently, "W group”, specifically for women, was launched. Members can freely participate in any of the group activities based on their interests.

\begin{tabular}{|l|l|l|l|}
\hline \multicolumn{2}{|c|}{ Occupation } & \multicolumn{2}{c|}{ Organization } \\
\hline Software Engineer & $43.4 \%$ & Microsoft & $27.6 \%$ \\
\hline Product Manager & $14.7 \%$ & Amazon & $24.6 \%$ \\
\hline Researcher & $11 \%$ & Startups & $17.2 \%$ \\
\hline Marketing/Management & $10.3 \%$ & Other & $22.7 \%$ \\
\hline Designer & $7.4 \%$ & UW & $6 \%$ \\
\hline Engineer & $3.7 \%$ & $\begin{array}{l}\text { Other } \\
\text { universities }\end{array}$ & $3 \%$ \\
\hline
\end{tabular}

Table 1. CB Membership Occupation and Organization

The core activity of CB since its establishment is a monthly seminar that provides members opportunities to interaction and learn. CB members or external speakers are invited to present on topics closely related to their expertise, followed by an active Q\&A session. Seminar topics include comparisons of career environments between Korea and the US, mobile media trends, and social entrepreneurship and technology. An example of a major CB event is a conference titled "Connect Un-connected" in October of 2016 that emphasized networking. The conference was open to the public and provided a mix of learning and social activities. Seminars are uploaded to the official website and open to the public to encourage learning. In addition to CB wide events, each subgroup organizes their own monthly seminar based on the specific interest of its members.

\subsection{Data Collection}

A member of the research team is a Korean national and occasional participant in CB. The research team gained access to $\mathrm{CB}$ documentation and members through CB's leadership team who distributed calls for voluntary participation in the study. The preliminary data was collected from multiple sources. We conducted interviews, focus groups and collected documentation (website and facebook page). To understand the catalysts for CB, CB members' motivation for joining $\mathrm{CB}$, and how CB meets members' needs, we conducted nine semi-structured interviews with CB leaders and members. Leaders' interviews included the founder, current president, and four subgroup leaders (designer, developer, entrepreneur, and $\mathrm{W}$ groups). Interviews with members included representatives from the designer, developer, and entrepreneur subgroups. We also conducted a focus group to understand designers' perspectives on their own subgroup and CB. 


\subsection{Data analysis}

We analyzed the data using a mix of deductive and inductive content analysis methods, employing Miles and Huberman's interactive model [37]. We developed a coding scheme based on our understanding of CoPs and AGs (presented in Appendix A). The coding scheme was refined (new categories added, deleted, or revised) based on the content analysis of the data to allow for new themes to emerge and refine the initial content analysis framework in Appendix A. The paper reports on the preliminary stage of the data analysis and focus on interview and focus groups notes and documentation.

\section{Results}

Using the $A G$ and CoP lenses (synthesized in Appendix A) we analyzed CB's characteristics. The remainder of this section reports on our findings related the each of the five dimensions of AGs and CoPs.

\subsection{Purpose}

While the purpose of AGs is to provide social support and networking within a group that shares a common attribute such as national culture, CoPs focus on learning through practice. In the case of $\mathrm{CB}$, the group meets the purposes of both AGs and CoPs. The vision statement on CB's homepage explicitly states that the purpose of $\mathrm{CB}$ is "learning and mutual growth of its members through networking”, and all nine interviewees and the focus group participants clearly stated the dual purpose CB plays.

All members in the interviews and focus group emphasized that the combination of social support within a Korean group and learning experiences was critical for their participation in CB. One of the focus group participants explained: "I tried to search $U X$ meetups or groups to join in, even attended several conferences, but they were mainly event-based and not continued to some social groups. But in Korea, there are a lot of groups like CB and it is very common. (...) There are a lot [of this kinds of groups] in companies and also in social networks."

It is evident from this comment that CB emulates communities in Korea that provide social and professional support which CB members are seeking to replicate here in the US. All six leaders interviewed stressed that affinity through nationality of members was key to facilitate both networking and learning within the group. In the interviews, leaders explicitly mentioned that sharing the same nationality, Korean, was important to develop a learning culture of CB. One leader articulated, "the same ethnicity gives stability [for its members], and based on that, learning across the members can be active." According to another leader, "The whole concept of $C B$ is that Koreans who have been raised and educated in Korea feel more comfortable among Koreans. Thus, they can learn how to do better [and] simulate in the fields by learning from Koreans."

When asked why they chose CB over other CoPs in their organization, members explained that social networking with people who speak the same language provided more opportunities for continuous learning outside of the organization. One focus group participant explained, "[in company groups for social and learning], it is just the similar situation [to work]. But in $C B$, we are speaking Korean, speak more freely, and [less] cultural differences...”

While AG focuses on social support and networking, $\mathrm{CoP}$ focuses on learning through practice. In the case of $\mathrm{CB}$, the group contains the characteristics of both AG and CoP. The vision statement on their homepage explicitly mentions the purpose of CB as "learning and mutual growth of its members through networking”, and all nine interviewees and three focus group participants clearly recognized the purpose.

\subsection{Dimensions and Phases}

The preliminary data revealed an interesting blend of CoP and AG dimensions and processes in CB. Below is a discussion of the main highlights that illustrate the most salient characteristics consistent with CoP and AG dimensions revealed through our analysis of CB.

4.2.1. Domain and Awareness. Domain in CoPs refers to the shared interest or practice and awareness in AGs to the type of shared attribute that define the group. Korean nationality and the IT profession are the core shared attributes that bind the group. The Korean culture is an important common ground for socialization and support among CB members. Many interviewees mentioned that sharing the same culture positively influenced social interactions within the group. One leader said, "it is not about the ability of communication in English, but we sometimes want to speak in Korean because we want to feel comfortable." Similarly, another leader mentioned, "we are grown up as Korean, not American. [As a Korean,] I need [to be] where I'm being comfortable." A focus group participant expressed, "[in workplace], I would not feel comfortable to do too much activities with company people. I don't know what I really can share or what not to share (...) I talk little less sometimes, but in $C B$, who cares?"

The domain that further binds $\mathrm{CB}$ is their IT professional background. Initially, CB was comprised mainly of software developers. As the group evolved, 
they attracted Korean IT professionals from various specialties. The diversification of interests led to diversification of activities meeting a breadth of topics beyond software engineering. For example, a member mentioned that some seminar topics were not relevant to her expertise. Moreover, a high degree of topic diversity did not always satisfy deeper level learning according to a member who said, "The depth of knowledge presented in the seminar often did not reach enough level that some expert developers would expect."

To address the issue of breadth vs. depth of knowledge, CB recently created three subgroups: designer, developer, and entrepreneur in which technical depth and knowledge sharing can take place and still satisfy the learning needs of members. Leaders stated that restructuring is intended "to create balance between the breadth and depth of knowledge" to meet the diverse interests of CB members. The three subgroup leaders had autonomy to choose topics based on specific needs of the subgroup members to enhance the depth in learning and knowledge sharing. CB members could attend any general $\mathrm{CB}$ and subgroup activities.

4.2.2. Community, Access and Affiliation. CoP literature stress regular interaction among group members to develop a sense of community. Similarly, AG literature emphasizes access to a broader network in the community and developing a sense of affiliation within the community through interaction. In CB, leaders facilitate social and professional interactions between members through a variety of monthly activities (e.g. seminars, gatherings) to enhance relationships and mentoring in order to strengthen the community and meet members' needs for affiliation with other Koreans. These affiliations and sense of community develop through interactions related to learning and knowledge sharing related to IT. One of the leaders stated: "[IT] is hot industry, lots of things are happening, (...) so, it is a good theme. We can have seminar that gives good motivation to people to join in. Happy hour, networking, (...) [through these] we can increase bond among people. In $C B$, we do active activities and gatherings." He added, "With the same background, the same interest, and the same culture, if we get together, we can learn from each other, grow together, and give back to the community".

A subgroup leader also stated: "I have two goals. The first one is to get together, and the second one is a more design-focused. (...) Transformation from information to knowledge is up to individual. I want people to share the information about what they are doing in the company, how do they design..." This particular leader plans activities such as gallery walks, collaborative presentations, and artwork production, which not only strengthen the sense of community and support within the subgroup but also expose members to visual design concepts.

4.2.3. Practice and Advancement. The practice and advancement dimensions of CoPs and AGs refer to the repertoire of resources, tools, and development of members' knowledge, expertise and leadership. CB emphasizes and provides educational activities that enhance members' expertise and leadership. CB does so through volunteer-based seminars presented in monthly face-to-face meetings announced via email, Facebook, and CB website). During the seminars presenters and members share their practice and knowledge related to a particular IT topic area. Engagement in Q\&A session post presentations encouraged members to broaden their perspectives and enhanced their expertise.

Each subgroup creates different learning experiences and social interaction depending on its needs and area of practice. For example, both leader and member of the developer subgroup agreed that they mainly interacted through a series of seminars to share knowledge. Topics centered on software engineering topics to satisfy members' interests. The Designer group prioritized social networking and create collaborative learning experiences in the design domain more suitable for the practice of design. Entrepreneur group emphasized projects in order to apply and further develop member knowledge (e.g., two or three members in the group created a small team to write a book).

Furthermore, it is evident that in CB, advancement is not just geared towards technical knowledge but leadership skills as well. CB leaders develop and mentor potential future leaders of CB. W group leader discussed how the current president of CB encouraged her to lead the $\mathrm{W}$ group, and the other leaders provided social support to prepare her for the role. This particular instance is an example of the LPP model. In the beginning, she observed how other leaders carried out basic tasks and duties. Other leaders were welcoming and provided detailed constructive feedback. As she became familiar with the responsibilities, she developed her leadership practices and was able to assume her leadership role. Moreover, engagement in the community over time enables members to move from novice status in their expertise to expert status and to share their own learning. One of the focus group participants explicitly mentioned that "I learn a lot from [general] seminar, but for my subgroup, I want to share what I know with others because I have experience in this field" and he was willing to give presentations related to his if his expertise (e.g., visual design) in order to help other CB members. 


\subsection{Membership}

CB restricts membership to Koreans because members' nationality was critical to encourage social networking and learning. This is best illustrated by the following quote from a CB leader: "Korean American cannot be the members of CB. Only Koreans who share the same culture can join." Another leader added, "In my view, the official goal of $C B$ is to gather a group of Koreans, who are not Korean Americans, who have a distinction between American and Korean culture." CB further restricts membership to those within the IT industry.

Although CB is open to all Koreans in IT across gender and age, there appears to be some differences in participation, needs, and perceptions between age groups and gender. A member in his early 30s, married with no children, said that he did not join the Korean lunch gathering in his workplace and joined CB instead because "The main members [in the Korean lunch group at work] are in late 30-40s and the main topic of the conversation is mostly about their children, which is hard to join in." Another member in her late 20s mentioned that the average age of CB was a little older and other members' interests sometimes did not overlap with hers. She added, "There are not many female members in my age in $C B$, and that is why I am seeking for social groups in my age other than the CB."

The data from interviews revealed that leaders were aware of members' different needs and interests and membership is influenced by age, gender, and life-stage. The intersectional differences of the members by age, gender and life-stage prompted $\mathrm{CB}$ to create the $\mathrm{W}$ group, mainly targeting female employees in their late 20s and early 30s. The $\mathrm{W}$ group leader emphasized the need to create a comfortable environment for young Korean females in IT because the majority of CB leaders and membership were mostly males in their 30-40s.

\subsection{Organizational context}

Currently, CB is independent of any organizational context. Six out of nine interviewees pointed out that CB's inter-organizational characteristic presented both benefits and limitations for the community. The most apparent benefit is that members can access a wide breadth of knowledge and network. In monthly seminars, Amazon, Google, or Facebook employees share their expertise and promote systems and practices of a wide range of companies. All nine interviewees agreed that this type of exposure broadened their knowledge and practices. Limitations of interorganizational communities often emerge when knowledge and practice shared do not suite the members' current organizational practices.

\section{Discussion}

Our results revealed insights about the characteristics of this emerging form of CoPs and AGs that we will refer to as Affinity Community of Practice (ACoP). These findings have implications for CoPs and AGs and perhaps suggest the need for ACoPs in the IT industry. In the remainder of this paper we will discuss the implications of our preliminary findings and future research plans.

\subsection{The combination of affinity and practice enhances learning}

Perhaps most striking about our preliminary results is the significant emphasis on national culture as a key dimension of CB. According to the interviews and focus group, members stressed that CB emulated other groups (e.g. learning circles and meet-up groups) in Korea, which encouraged member to join CB. CB leaders recognized that the affinity to national culture facilitated the development of social ties among Korean IT professionals. As such, leaders emphasized that "being comfortable in the group" that shares the same national culture would eventually facilitate members' learning within the community. This is what Gannon [38] called cultural mindset, including "basic ways of thinking, feeling, and acting that occur simply because of the fact that people are members of particular society." Sharing the same cultural mindset not only creates strong social ties among community members but also enhances efficiency in intellectual communications, which implies the importance of combining learning and social needs for migrant communities within IT. The social and national affiliation extended to include members' spouses and families in social events such as annual summer barbeque.

Learning about IT practices in CB is intertwined with sharing national cultural stories, symbols, and role models consistent of CoP concepts. In monthly seminars, speakers shared not only knowledge of their technical expertise, but also personal experiences, such as career development in the US. Being exposed to the stories of successful figures with the same nationality improves the self-efficacy of group members.

In the analysis we also witnessed instances of legitimate peripheral participation [7] in CB especially in learning about leadership practices as in the case described in the discussion section about the socialization of the leader of the $\mathrm{W}$ group. This raises the questions of whether mentoring and apprenticeship might be more effective between those who share national background amongst the immigrant IT professionals.

ACoPs afford exposure to a broader set of knowledge and practices due to inter-organizational 
membership [25, 26]. Sharing the same nationality helped CB leaders create networking with Korean IT employees/employers from other groups (i.e., K-group) in different US regions, such as Silicon Valley. It seems that national culture fosters organizational proximity that "allows [individual's] coordination without having definition beforehand how to do so [27]”. The authors mentioned [27:76], "When organizational cultures are similar, organizations are expected to interact more easily and with better results, because common interpretations and routines allow organizations to interpret and give meaning to actions without making all these difficult interpretations explicit." Common national culture among members could be a conduit to interpreting practice and knowledge across organizations that may differ in organizational culture but have ACoPs in common. Sharing across organizational boundaries however leave some organizations vulnerable to sharing proprietary information. More research is needed in this area.

Sharing the same national culture, however, has limitations. Some CB leaders cautioned that sharing the same cultural mindset might limit group members' perspectives, which might prevent innovation in the long term. Also, observable differences in gender, age, and life stage might create barriers to inclusion for some members [33, 39], which led CB leaders to create another affinity group (i.e. $\mathrm{W}$ group) to minimize the negative impact of gender and age on the community.

\subsection{Balancing depth and breadth across domain and practice while building affinity}

The main goal of $\mathrm{CB}$ is to enhance learning and knowledge sharing between Korean IT professionals. As indicated in the results section, balancing multiple areas of expertise in IT is no easy task. Our results echoed the literature in that skill-based or knowledgebased diversity broadens members' perspectives to improve learning and creativity [39]. However, that diversity may also create difficulties in interaction and a low level of behavioral integration [39]. Hence, managing the breadth and depth of technical knowledge is crucial to creating and sustaining learning experiences within a community. CB achieves this balance by creating learning opportunities for breadth (using general CB activities) and depth (using subgroup activities) and allowing members to attend the subgroup that suits their needs across the various subgroups. By creating three domain-based subgroups (i.e., developers, designers, and entrepreneurs) under an overarching community, $\mathrm{CB}$ maintained the social aspect of the community among members while providing members the freedom to pursue the depth of knowledge related to their interest.

\section{Conclusion}

In this paper we reported on the preliminary findings of a case study investigating an emerging form of CoPs that combines dimensions of AGs. These initial findings have practical and theoretical implications for CoPs, AGs and ACoPs. Our findings suggest that some IT migrant employees seek learning and professional development in the context of a supportive affinity group with a shared national culture. Our preliminary findings suggest the need to balance social support and learning activities when designing CoPs for a diverse migrant community of professionals. Additionally, the findings suggest that more data collection is needed to further elaborate on the question of why members of CB prefer it over CoPs within their companies. Furthermore, the results indicate that, in order to be effective, there is a need for a diversity of activities within CoPs to meet the knowledge sharing and learning modes of any specific knowledge domain. Further data collection and analysis will better explain the suitability and inform the design and management of ACoPs to meet the needs of migrant and other marginalized IT professionals.

\section{References}

[1] The US visa department. "Worldwide H1B, H2A, and H2B Visa Issuances Fiscal Years 2011-2016.” [Online]. Available: https:/travel.state.gov/content/dam/visas/Statistics/Graphs/H \%20VisasWorldwide.pdf. [Accessed: 15-Jun-2017]

[2] U.S. Citizenship and Immigration Services, "H-1B Trends: 2007 to 2017.” [Online], Available: https://www.uscis.gov/sites/default/files/USCIS/Resources/R eports\%20and\%20Studies/Immigration\%20Forms\%20Data/ BAHA/h-1b-2007-2017-trend-tables.pdf. [Accessed: 05-Sep2017]

[3] The US visa department. "Nonimmigrant Visa Issuances by Visa Class and by Nationality." Internet: https://ravel.state.gov/content/dam/visas/Statistics/NonImmigrant-

Statistics/NIVDetailTables/FY16\%20NIV\%20Detail\%20Tab le.pdf. [Accessed: 15-Jun-2017]

[4] P. H. Douglas, "Affinity groups: Catalyst for inclusive organizations,” Employ. Relat. Today, vol. 34, no. 4, pp. 1118, 2008.

[5] V. J. Powers, "Xerox creates a knowledge-sharing culture through grassroots efforts," Knowledge Management in Practice, 1999.

[6] T. M. Welbourne, S. Rolf, and S. Schlachter, “'Employee Resource Groups: An Introduction, Review and Research Agenda'," Academy of Management Proceedings, vol. 2015, no. 1, pp. 15661-15661, Sep. 2015.

[7] J. Lave and E. Wenger, Situated Learning. Cambridge University Press, 1991. 
[8] E. C. Wenger and W. M. Snyder, "Communities of practice: The organizational frontier," Harvard business review, vol. 78, no. 1, pp. 139-145, 2000.

[9] R. A. Friedman and K. M. Craig, "Predicting Joining and Participating in Minority Employee Network Groups," Industrial Relations, vol. 43, no. 4, pp. 793-816, Oct. 2004.

[10] M. M. Kaplan, E. Sabin, and S. Smaller-Swift, The Catalyst Guide to Employee Resource Groups. Volume 1: Introduction to ERGS, 2009.

[11] S. Goode, "Are Employee Resource Groups Good for Business?,” HR Magazine, pp. 24-25, Sep-2016.

[12] T. M. Welbourne and L. L. McLaughlin, "Making the Business Case for Employee Resource Groups,” Employ. Relat. Today, vol. 40, no. 2, pp. 35-44, Jun. 2013.

[13] Mercer, "ERGs come of age: The evolution of employee resource groups,” 2011 [Online]. Available: http://www.orcnetworks.com/system/files/story/2011/5849/er gs_come_of_age_2011_study_pdf_30909.pdf. [Accessed: 15Jun-2017]

[14] M. Scully and A. Segal, "Passion with an umbrella: Grassroots activists in the workplace," Social Structure and Organizations Revisited, vol. 19, pp. 125-168, 2002.

[15] F. Briscoe and S. Safford, "Employee Affinity Groups: Their Evolution from Social Movement Vehicle to Employer Strategies,” Members-only Library, vol. 14, no. 1, Jan. 2015.

[16] R. A. Friedman and B. Holtom, "The effects of network groups on minority employee turnover intentions," Hum. Resour. Manage., vol. 41, no. 4, pp. 405-421, Dec. 2002.

[17] E. Wenger, Communities of practice: a brief introduction. 2006.

[18] E. Wenger, R. McDermott, and W. Snyder, Cultivating communities of practice: A guide to managing knowledge. Boston: Harvard Business School Press, 2002.

[19] H. Annabi and S. T. McGann, "Social media as the missing link: Connecting communities of practice to business strategy," Journal of Organizational Computing and Electronic Commerce, vol. 23, no. 1, pp. 56-83, 2013.

[20] S. BORZILLO, G. PROBST, and S. RAISCH, "THE GOVERNANCE PARADOX: BALANCING AUTONOMY AND CONTROL IN MANAGING COMMUNITIES OF PRACTICE.,” Academy of Management Proceedings, vol. 2008, no. 1, pp. 1-6, Aug. 2008.

[21] E. Wenger, Communities of Practice. Cambridge University Press, 1998.

[22] J. S. Brown and P. Duguid, “Organizational learning and communities-of-practice: Toward a unified view of working, learning, and innovation,” Organization Science, vol. 2, no. 1, pp. 40-57, 1991.

[23] C. Benner, "Learning Communities in a Learning Region: The Soft Infrastructure of Cross-Firm Learning Networks in Silicon Valley,” Environment and Planning A, vol. 35, no. 10, pp. 1809-1830, Oct. 2003.

[24] W. W. Powell, K. W. Koput, and L. Smith-Doerr, "Interorganizational collaboration and the locus of innovation: Networks of learning in biotechnology," Administrative science Quarterly, vol. 41, no. 1, p. 116, 1996.

[25] M. Soekijad, M. A. A. Huis in 't Veld, and B. Enserink, "Learning and knowledge processes in inter - organizational communities of practice," Knowledge and Process Management, vol. 11, no. 1, pp. 3-12, Jan. 2004.
[26] M. Easterby-Smith, M. A. Lyles, and E. W. K. Tsang, "Inter - Organizational Knowledge Transfer: Current Themes and Future Prospects,” J Management Studies, vol. 45, no. 4, pp. 677-690, Jun. 2008.

[27] J. Knoben and L. A. G. Oerlemans, "Proximity and interorganizational collaboration: A literature review," International Journal of Management Reviews, vol. 8, no. 2, pp. 71-89, 2006.

[28] W. E. Watson, L. Johnson, and G. D. Zgourides, “The influence of ethnic diversity on leadership, group process, and performance: an examination of learning teams," International Journal of Intercultural Relations, vol. 26, no. 1, pp. 1-16, Feb. 2002.

[29] W. E. Watson, K. Kumar, and L. K. Michaelsen, "Cultural Diversity's Impact On Interaction Process and Performance: Comparing Homogeneous and Diverse Task Groups,” ACAD MANAGE J, vol. 36, no. 3, pp. 590-602, Jun. 1993.

[30] R. J. Ely and D. A. Thomas, "Cultural Diversity at Work: The Effects of Diversity Perspectives on Work Group Processes and Outcomes," Administrative science Quarterly, vol. 46, no. 2, p. 229, Jun. 2016.

[31] M. E. A. Jayne and R. L. Dipboye, "Leveraging diversity to improve business performance: Research findings and recommendations for organizations,” Hum. Resour. Manage., vol. 43, no. 4, pp. 409-424, 2004.

[32] A. M. Konrad, "Leveraging Workplace Diversity in Organizations,” Organization Management Journal, vol. 3, no. 3, pp. 164-189, Dec. 2006.

[33] F. Kunze, S. A. Boehm, and H. Bruch, "Age diversity, age discrimination climate and performance consequences-a cross organizational study," Journal of Organizational Behavior, vol. 32, no. 2, pp. 264-290, 2010.

[34] Catalyst, "Making every day count: Driving business success through the employee experience," Catalyst, 2012.

[35] J. Roberts, "Limits to Communities of Practice," J Management Studies, vol. 43, no. 3, pp. 623-639, May 2006. [36] R. K. Yin, Case Study Research: Design and Methods, 3rd ed. Thousand Oaks: SAGE Publications, 2003.

[37] M. B. Miles and A. M. Huberman, "Qualitative Data Analysis: A Sourcebook of New Methods," Educational Evaluation and Policy Analysis, vol. 8, no. 3, p. 329, 1986. [38] M. J. Gannon, Understanding Global Cultures: Metaphorical Journeys Through 17 Countries. SAGE, 1994.

[39] F. J. Milliken and L. L. Martins, "Searching for common threads: Understanding the multiple effects of diversity in organizational groups," Academy of Management Review, vol. 21, no. 2, pp. 402-433, 1996. 


\section{Appendix A: Comparison of AG and CoP Characteristics Applied to CB}

\begin{tabular}{|c|c|c|c|}
\hline & AGs & CoPs & CB \\
\hline Purpose & $\begin{array}{l}\text { Provide social support for members who share a } \\
\text { common characteristic }[4,10,12] \text {. Shared } \\
\text { characteristics relate to members' identity including } \\
\text { personal characteristics, social purpose/cause, and } \\
\text { professional/career [12]. }\end{array}$ & $\begin{array}{l}\text { "To create, expand, and exchange knowledge, and to } \\
\text { develop individual capabilities” [18]( pp. 42), }\end{array}$ & $\begin{array}{l}\text { Provide opportunity for individual growth through } \\
\text { formal and informal learning and networking in a } \\
\text { supportive shared cultural environment. }\end{array}$ \\
\hline Dimensions & $\begin{array}{l}\text { AGs have four main dimensions/overlapping phases } \\
\text { including: } \\
\text { - Awareness refers to deciding the numbers and } \\
\text { characteristics of membership. } \\
\text { - Affiliation refers to community building and } \\
\text { connecting. } \\
\text { - Access refers to the ways diversity of network } \\
\text { increases and structured mentoring appears. } \\
\text { - Advancement refers to the education, training, and } \\
\text { leadership activities provided. }\end{array}$ & $\begin{array}{l}\text { CoPs have three main dimensions including: } \\
\text { - Domain represents a specific field of shared interest } \\
\text { which members develop commitment to and } \\
\text { expertise in. } \\
\text { - Community refers to the nature of relationships } \\
\text { established between members through interactions. } \\
\text { - Practice refers to "a shared repertoire of resources } \\
\text { including experiences, tools, and ways of } \\
\text { addressing recurring problems" that are the central } \\
\text { focus of CoPs [17]. }\end{array}$ & $\begin{array}{l}\text { CB incorporates both AG and CoP dimensions as } \\
\text { follow: } \\
\text { - } \quad \text { In CB, CoP Domain is the IT field and more } \\
\text { specific sub areas including software } \\
\text { engineering, UX and visual design, and startup } \\
\text { (entrepreneurs). Related to CoP domain is AG } \\
\text { awareness that CB specifically serves for } \\
\text { Korean IT employees in the Seattle area. } \\
\text { - Community in CoP and Access and Affiliation } \\
\text { in AG are developed through regular monthly } \\
\text { interactions around learning activities, } \\
\text { networking and social activities in CB. } \\
\text { Practice in CoP and Advancement in AG } \\
\text { cover a range of IT related experiences, skills, } \\
\text { tools and career stories shared within the } \\
\text { subgroups and larger group in CB. } \\
\text { An important dimension of CB community is sharing } \\
\text { Korean culture. The community dimension and social } \\
\text { support meets the AG characteristic and is a unique } \\
\text { element that draws the members to join the group. }\end{array}$ \\
\hline Membership & $\begin{array}{l}\text { Membership is often voluntary and based on shared } \\
\text { identify characteristic or interest e.g. ethnicity, } \\
\text { nationality, gender, sexual orientation, interest in } \\
\text { gaming, service [4]. }\end{array}$ & $\begin{array}{l}\text { Membership is often voluntary based on interested in } \\
\text { the domain. Novice members learn through } \\
\text { interaction with and observation of experts in the } \\
\text { community, and eventually become contributing } \\
\text { members and full participants [7]. }\end{array}$ & $\begin{array}{l}\text { Membership is voluntary and based on nationality is } \\
\text { required; any Korean employee who works in the IT } \\
\text { field is eligible to apply for the membership. }\end{array}$ \\
\hline Formality & $\begin{array}{l}\text { AGs are often formal initiatives initiated at the } \\
\text { corporate level [4]. }\end{array}$ & $\begin{array}{l}\text { CoPs may be formal or informal and inter or intra } \\
\text { organizational. CoPs may also be a result of } \\
\text { grassroots effort or a formal organizational initiative. }\end{array}$ & $\begin{array}{l}\text { CB is an informal grassroots effort without any } \\
\text { organizational sponsorship. }\end{array}$ \\
\hline $\begin{array}{l}\text { Organization } \\
\text { context }\end{array}$ & $\begin{array}{l}\text { AGs are largely formal groups within organizations } \\
\text { [9], [10] and represents the employee's need for a } \\
\text { self-led support network. }\end{array}$ & $\begin{array}{l}\text { CoPs can be either inter- or intra-organizational } \\
\text { depending on the context of learning and desires of } \\
\text { the community. }\end{array}$ & $\begin{array}{l}\text { CB is inter-organizational community with no } \\
\text { organizational sponsorship. }\end{array}$ \\
\hline
\end{tabular}

